\title{
Effect of Contrast Agent Administration on Size-Specific Dose Estimates (SSDE) Calculations based on Water Equivalent Diameter in CT Head Examinations
} Moh. Shofi Nur Utami ${ }^{*}$, Heri Sutanto ${ }^{1}$, Choirul Anam ${ }^{1}$, Muharam Budi Laksono ${ }^{2}$

1Department of Physics, Faculty of Science and Mathematics, Diponegoro University, Semarang, Indonesia 2Department of Radiology, Rumah Sakit Umum Daerah Majalengka, Majalengka, Indonesia

\section{Article Info}

Volume 8, Issue 3

Page Number : 563-571

\section{Publication Issue}

May-June-2021

\section{Article History}

Accepted : 03 June 2021

Published : 08 June 2021

\section{ABSTRACT}

Size-specific dose estimate (SSDE) is dose metrics of computed tomography, to calculate SSDE we first calculate the patient's body size. In CT head examination, the head size is better to use water-equivalent diameter (Dw), because Dw considers tissue attenuation. CT Head examination with contrast agent increased patient attenuation and increased Dw. In this study, we observed the effect of contrast agent on the Dw value on the axial image of patients with CT head examination. A total of 96 patients underwent a CT Head examination with a contrast agent in the two CT scan modalities. 46 patients underwent CT Head examination with contrast agent using CT Scanner Toshiba Alexion 16 and 50 patients underwent CT Head examination with contrast agent using CT Scanner GE Medical System Optima CT660. Dw value is calculated automatically using IndoseCT version $20 \mathrm{~b}$. We compared the Dw pre-contrast and Dw post-contrast values with the two independent sample t-test statistical analysis. To consider the effect of changing Dw values on SSDE we normalized dose coefficient (NDC). We did not find a significant difference between $\mathrm{Dw}$ pre-contrast and Dw post-contrast. The P-value statistical analysis results for the CT Scanner Toshiba Alexion 16 and the CT Scanner GE Medical System Optima CT660 were 0.65 and 0.45. The NDC change in this study was below $20 \%$. On CT Head examination, the Dw and SSDE pre-contrast values can be used to estimate the Dw and SSDE postcontrast values.

Keywords : CT Head, water-equivalent diameter, size-specific dose estimate

\section{INTRODUCTION}

CT scanning has been widely used in medical imaging to help detect and make medical decisions [1]. In certain cases, if a suspicious lesion is present on non- contrast computed tomography of the head (NCTH), a contrast agent is required to supplement the information obtained [2]. However, additional exam with a contrast agent on a CT increases the radiation dose received by the patient $[3,4]$. Therefore, 
accurate quantification of the radiation dose received by a patient is crucial.

Volumetric computed tomography dose index (CTDIvol) and dose length product (DLP) are dose metrics that have been used to quantify the radiation dose of CT [5,6]. These two metrics do not take into account patient characteristics, hence the dose metrics only indicate the CT output dose and not the absorbed dose by the patient [7-9]. Meanwhile, the dose absorbed by the patient should take into account the CT output dose and patient characteristics [10-13] In 2011 the American Association of Physicists in Medicine (AAPM) Report No. 204 introduced a sizespecific dose estimate (SSDE) as a dose metric that takes into account the CT dose output and patient characteristics [14]. SSDE is computed from the CTDIvol value multiplied by the patient characteristic conversion factor (f) [15]. The characteristic conversion factor on the AAPM RPT 204 is the patient's body diameter or the patient's effective diameter (Deff) which can be determined by measuring the patient's lateral (LAT) and anteriorposterior (AP) body diameters [16]. The concept of SSDE calculation based on Deff was developed for CT abdomen and pelvic CT examinations, however it can also be used for CT thorax with an error up to $20 \%$. To anticipate this error, AAPM Report No. 220 reported a new concept called water-equivalent diameter (Dw) as an extension of Deff. The Dw considers tissue attenuation to more accurately estimate SSDE in areas of the body that have various tissue densities and compositions, such as when used for CT Thorax examination [17]. Although SSDE has been used to represent organ dose in terms of abdominal scans [18]. AAPM Report No. 204 and AAPM Report No. 220 have limitations only on body CT examinations. Then in 2019, AAPM developed SSDE based on Dw with conversion factors according to CT head examination [19].

The value of Dw depends on the tissue attenuation of the X-rays, and in the image, it is expressed in the
Hounsfield unit (HU). When a contrast agent is injected, it will increase tissue attenuation and $\mathrm{HU}$ at some areas as shown in Figure 1. Increased tissue attenuation at some areas affects the Dw value. To the best of our knowledge, the scientific papers reporting on the effect of contrast agents administration on Dw are limited to CT abdomen and pelvic regions [20,21]. Therefore, we observed the effect of contrast agent on Dw values based on axial images of patients for CT head examination. In addition, the SSDE represents the absorbed dose along the $\mathrm{z}$-axis of the clinical CT will be examined. We also evaluated the SSDE using AAPM Report No. 293 that determined the new conversion factor value on CT head examination as a function of Dw so that the mire accurate brain estimation will be obtained [19]. It is hoped that this study can be used to consider Dw and SSDE values as a function of head conversion factors for CT head contrast examination.

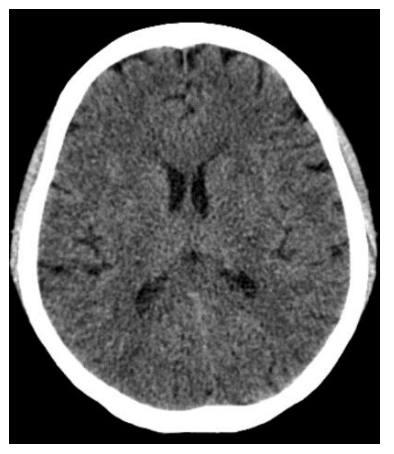

(a)

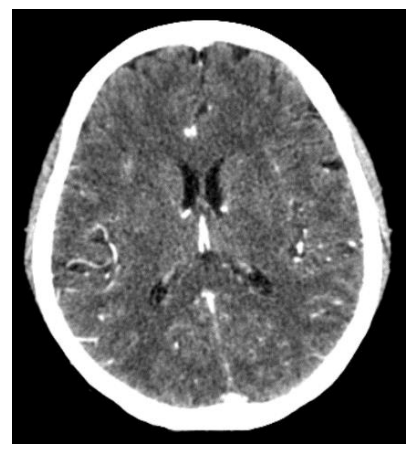

(b)
Figure 1: Image from CT brain in the same patient at WW/WL 80/40 HU. (a) without contrast agent and (b) with contrast agent.

\section{METHODS AND MATERIAL}

Patients have collected retrospectively from CT head and CT head contrast images in the DICOM file. We calculated the Dw value of the two CT modalities with a total of 96 patients. 46 patients underwent a CT head contrast examination with a Toshiba Alexion 16 CT Scanner installed at Cideres Hospital, 
Majalengka, Indonesia and 50 patients underwent a CT head contrast examination with a GE Medical System Optima CT660 CT Scanner which was installed at Permata Cirebon Hospital, Indonesia. Patients who underwent a CT head contrast examination with a Toshiba Alexion 16 CT Scanner consisted of 26 women and 20 men, aged between 15 - 78 years, and a mean weight of $56.58 \pm 10.10 \mathrm{~kg}$. Scanning parameters: head helical, tube voltage of 120 $\mathrm{kVp}$, tube current of $200 \mathrm{~mA}$, slice thickness of $1 \mathrm{~cm}$, rotation time of $0.75 \mathrm{~s}$, pitch of 0.688 , and convolution kernel of FC64, with CTDIvol $52.9 \mathrm{mGy}$. Meanwhile, patients who underwent CT head contrast examination with GE Medical System Optima CT660 CT Scanner consisted of 32 women and 18 men, with an age between 16 - 83 years and an average weight of $59.94 \pm 10.05 \mathrm{~kg}$. Scanning parameters: head helical, tube voltage of $120 \mathrm{kVp}$, tube current of $175 \mathrm{~mA}$, slice thickness of $1.25 \mathrm{~cm}$, rotation time of $0.8 \mathrm{~s}$, pitch of 0.53125 , and convolution kernel standard with CTDIvol 47.27 $\mathrm{mGy}$. The contrast agent solution of iodine with a concentration of $300 \mathrm{mg} / \mathrm{mL}$ (Iohexol, Omnipaque ${ }^{\mathrm{TM}}$ ) has been injected intravenously (IV).

The value of $\mathrm{Dw}$ is calculated from the region of interest (ROI) on the axial image of the patient using Equation (1).

$$
\mathrm{D}_{\mathrm{w}}=2 \sqrt{\left[\frac{1}{1000} \overline{\mathrm{CT}}+1\right] \frac{\mathrm{A}_{\mathrm{ROI}}}{\pi}}
$$

Where $\overline{\mathrm{CT}}$ is the mean HU value of the pixels in the patient's ROI, and $A_{R O I}$ is the area of the patient's ROI $\left(\mathrm{mm}^{2}\right)$. The shape of the ROI follows the contours of the patient, automatic contouring using the IndoseCT version 20b as shown in Figure 2. Dw values can be calculated using the entire slice or only one middle slice for chest examination [22]. However, in the head examination, the Dw counted on the middle slice is always greater than the Dw counted over the entire slice [23]. Therefore, in this study we used all slices to calculate the Dw value. We assume that calculating Dw on all slices can represent the effect of the contrast agent on the mean value of Dw.
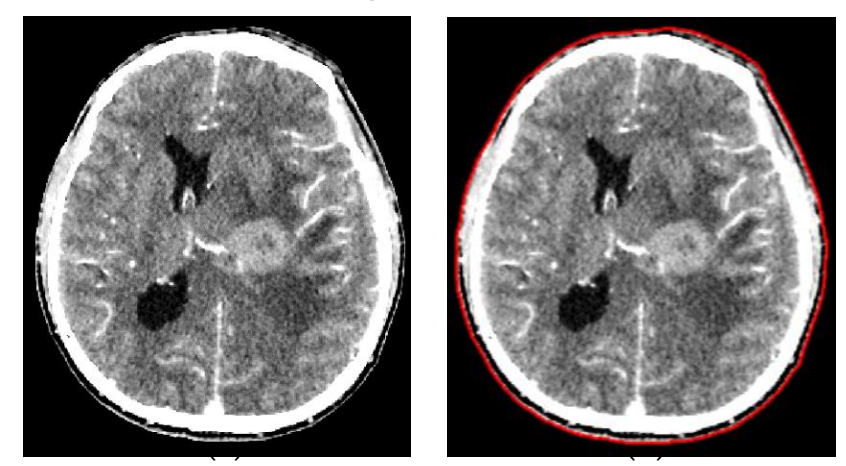

Figure 2: Image Processing by IndoseCT to applied auto-contouring (a) before auto-contouring and (b) after auto-contouring.

The conversion factor ( $f$ ) used in this study is obtained from the AAPM Report 220 body conversion factor ( $\mathrm{f}^{\mathrm{B} 16}$ ) Equation (2) [17] and AAPM Report 293 head conversion factor $\left(\mathrm{f}^{\mathrm{H} 16}\right)$ Equation (3) [19].

$$
\begin{gathered}
\mathrm{f}^{\mathrm{B} 16}=1.874799 \times \mathrm{e}^{-0.03871313 \mathrm{D}_{\mathrm{w}}} \\
\mathrm{f}^{\mathrm{H} 16}=1.9852 \times \mathrm{e}^{-0.0486 \mathrm{D}_{\mathrm{w}}}
\end{gathered}
$$

SSDE is obtained by multiplying the conversion factor value with the CTDIv value from the dose report according to Equation (4).

$$
\operatorname{SSDE}=\mathrm{CTDI}_{\mathrm{vol}} \times \mathrm{f}
$$

The $f$ value affects the absorbed dose received by the patient. This study identified differences in the use of $\mathrm{f}^{\mathrm{B} 16}$ and $\mathrm{f}^{\mathrm{H} 16}$ values to determine the absorption dose received by patients when undergoing CT head contrast examination. The SSDE value with the head conversion factor for the same CTDIv value was approximately $8.7 \%$ lower than the body conversion factor value [19].

The method in our study aims to identify differences in Dw CT head pre- and post-contrast agent. The effect of the contrast agent on Dw depends on the tube voltage. However, the effect of tube voltage after administration of contrast agent in Dw is very small, 
even at $140 \mathrm{kVp}$ there is no significant effect $[21,24]$. Therefore, we performed at $120 \mathrm{kVp}$. The data in this study were tested using the Shapiro-Wilk test for normality test. Regression analysis was used to determine the relationship between the Dw pre-and post-contrast values. In addition, a parametric test of two independent samples t-test was also conducted to determine the difference between the Dw pre- and post-contrast agent values. The confidence level is $95 \%$ $\mathrm{CI}$ or has a P-value of 0.05 . If the $\mathrm{p}$-value is $<0.05$, the two data tested are significantly different, and if the $P$-value is $\geq 0.05$, the two data tested are not significantly different. Statistical analysis was performed using IBM SPSS Statistics version 25 software.

Percent Difference (PD) was used to determine the difference between Dw pre-contrast and Dw postcontrast agent in percent and to calculate the difference between the conversion factors $\mathrm{f}^{\mathrm{B} 16}$ and $\mathrm{f}^{\mathrm{H} 16} \cdot \mathrm{PD}_{\mathrm{Dw}}$ is calculated using Equation (5), while $\mathrm{PD}_{\mathrm{f}}$ is calculated using Equation (6).

$$
\begin{gathered}
\mathrm{PD}_{\mathrm{Dw}}=\left(\frac{\mathrm{DwPOST}-\mathrm{DwPRE}}{\mathrm{DwPRE}}\right) \times 100 \% \\
\mathrm{PD}_{\mathrm{f}}=\left(\frac{\mathrm{f}^{\mathrm{H} 16}-\mathrm{f}^{\mathrm{B} 16}}{\mathrm{f}^{\mathrm{B} 16}}\right) \times 100 \%
\end{gathered}
$$

To consider the effect of Dw change on SSDE we normalized dose coefficient (NDC) fit parameters of the Appendix-1 AAPM report 220 for $\mathrm{f}^{\mathrm{B} 16}$ and Equation 1 AAPM report 293 for $\mathrm{f}^{\mathrm{H} 16}[17,19,20]$. $\mathrm{NDCf}^{\mathrm{B} 16}$ is calculated using Equation (7), while $\mathrm{NDCf}^{\mathrm{H} 16}$ is calculated using Equation (8).

$$
\begin{gathered}
\mathrm{NDCf}^{\mathrm{B} 16}=1-\mathrm{e}^{-\Delta \overline{\mathrm{Dw}} \times 0.03871313} \\
\mathrm{NDCf}^{\mathrm{H} 16}=1-\mathrm{e}^{-\Delta \overline{\mathrm{Dw}} \times 0.0486}
\end{gathered}
$$

Where $\Delta \overline{\mathrm{Dw}}$ is the difference between the mean value of Dw pre- and post-contrast.

\section{RESULTS AND DISCUSSION}

Figure 3 shows a positive relationship between the Dw pre-contrast value and the Dw post-contrast value for two CT Scan modalities, namely the Toshiba Alexion 16 CT Scanner and the GE Medical System Optima CT Scanner CT660 with $\mathrm{R}^{2}$ values were 0.9959 and 0.9776 . This indicates that the increase in the $\mathrm{Dw}$ pre-contrast value is accompanied by an increase in the $\mathrm{Dw}$ post-Contrast value. Table 1 reports the statistical analysis of the data tested in this study, the results of the test using two independent samples t-test to determine the difference between the Dw pre- and Dw post-contrast is the P-value for the Toshiba Alexion $16 \mathrm{CT}$ Scanner and the GE Medical System Optima CT660 were 0.65 and 0.45. Figure 4 shows the box and whisker plot of the Dw pre- and post-Contrast values. The difference between the mean Dw pre-contrast and the mean Dw post-contrast for the CT Scanner Toshiba Alexion 16 and the CT Scanner GE Medical System Optima CT660 were $0.43 \%$ and $0.73 \%$. From the three statistical analyzes, it was found that there was no significant difference between the Dw pre-contrast and $\mathrm{Dw}$ post-contrast values, this indicates that the contrast agent did not significantly influence the increase in the mean value of $\mathrm{HU}$ [25].

TABLE I

MEAN AND STANDARD DEVIATION OF THE DW

\begin{tabular}{|l|l|l|}
\hline CT Scanner & & \multicolumn{1}{c|}{ Dw (cm) } \\
\hline \multirow{4}{*}{$\begin{array}{l}\text { Toshiba } \\
\text { Alexion }\end{array}$} & Pre & $16.14 \pm 0.75$ \\
\cline { 2 - 3 } & Post & $16.21 \pm 0.73$ \\
\cline { 2 - 3 } & PD (\%) & 0.43 \\
\cline { 2 - 3 } & P-value & 0.65 \\
\hline GE Optima & Pre & $16.61 \pm 0.82$ \\
\cline { 2 - 3 } & Post & $16.74 \pm 0.78$ \\
\cline { 2 - 3 } & PD (\%) & 0.73 \\
\cline { 2 - 3 } & P-value & 0.45 \\
\hline
\end{tabular}



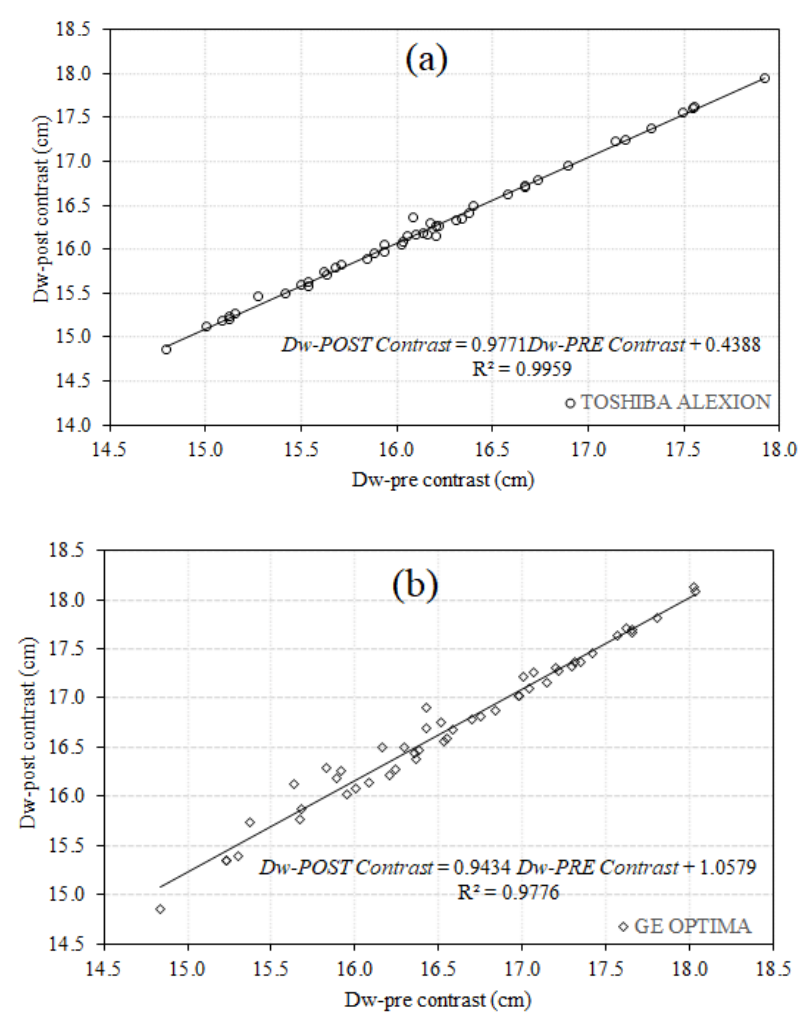

Figure 3: Scatterplot of water equivalent diameter pre-contrast vs water equivalent diameter postcontrast to know the relationship between them both.

(a) CT Scanner Toshiba Alexion 16. (b) CT Scanner GE Medical System Optima CT660.
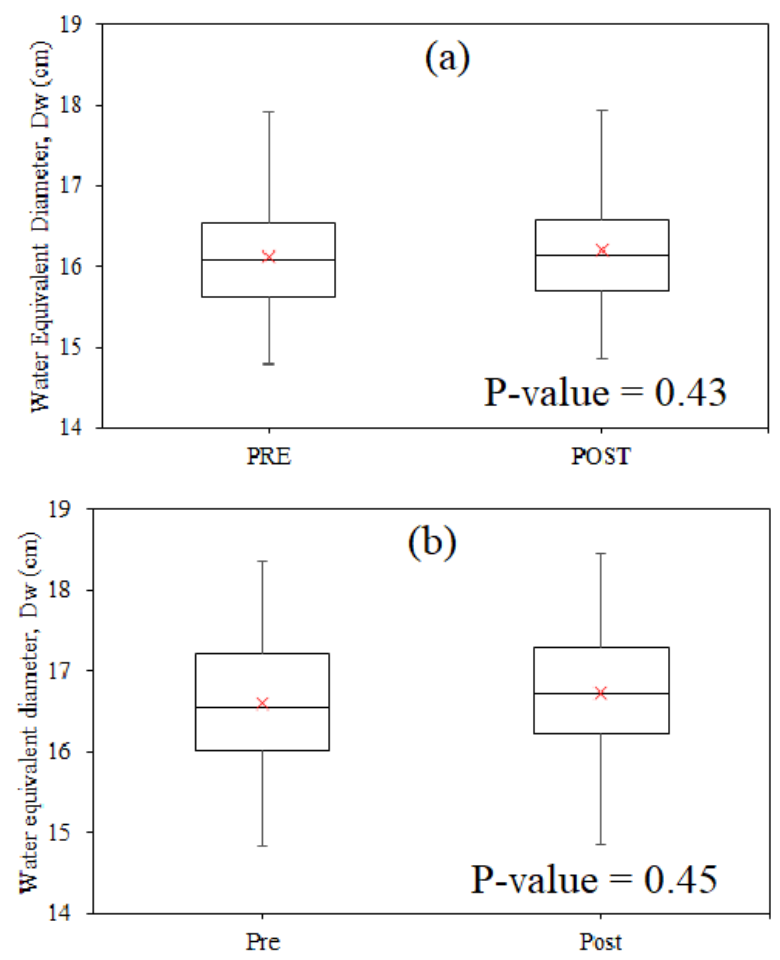

Figure 4: Box and whisker plot of water equivalent diameter pre- and post- contrast to know the relationship between them both. (a) CT Scanner Toshiba Alexion 16. (b) CT Scanner GE Medical System Optima CT660.

Figure 5 shows the conversion factor values ( $\mathrm{f}^{\mathrm{H} 16}$ and $\mathrm{f}^{\mathrm{B} 16}$ ) vs Dw for the two CT scan modalities. (a) data from Toshiba Alexion pre-contrast CT Scanner, $\mathrm{f}^{\mathrm{H} 16}$ 9.72\% smaller than $\mathrm{f}^{\mathrm{B} 16}$, (b) from CT Scanner, Toshiba Alexion post-contrast, $\mathrm{f}^{\mathrm{H} 16}$ 9.79\% smaller than $\mathrm{f}^{\mathrm{B} 16}$, (c) data from GE Optima pre-contrast CT Scanner, $\mathrm{f}^{\mathrm{H} 16} 10.08 \%$ smaller than $\mathrm{f}^{\mathrm{B} 16}$, and (d) data from the GE Optima post-Contrast CT Scanner, $\mathrm{f}^{\mathrm{H} 16}$ $10.19 \%$ smaller than $\mathrm{f}^{\mathrm{B} 16}$. Difference value between $\mathrm{f}^{\mathrm{H} 16}$ and $\mathrm{f}^{\mathrm{B} 16}$ in this study with a different value between $\mathrm{f}^{\mathrm{H} 16}$ and $\mathrm{f}^{\mathrm{B} 16}$ in AAPM Report No. 293 for Toshiba Alexion pre-contrast CT Scanner, Toshiba Alexion post-contrast CT Scanner, GE Optima precontrast CT Scanner and CT Scanner GE Optima postcontrast were $1.02 \%, 1.09 \%, 1.38 \%$, and $1.49 \%$. The difference in the value of this conversion factor is due to differences in the sampling method, AAPM Report No. 293 uses four sampling methods, the first of which was conducted at St. Jude Children's Research Hospital (Memphis, Tennessee) with physical measurements in Tissue-Equivalent Head Phantoms; the second was done at the Mayo Clinic with physical measurements in Tissue-Equivalent Head Phantoms; the third was conducted at the University of California-Los Angeles (UCLA) performing simulations with Monte Carlo Estimations in Voxelized Head Models; and a fourth performed at UC Davis performing a simulation with Monte Carlo Estimation in Virtual Head CT Phantoms [19]. However, this study took samples from axial images of patients in Indonesia and used a contrast agent. 

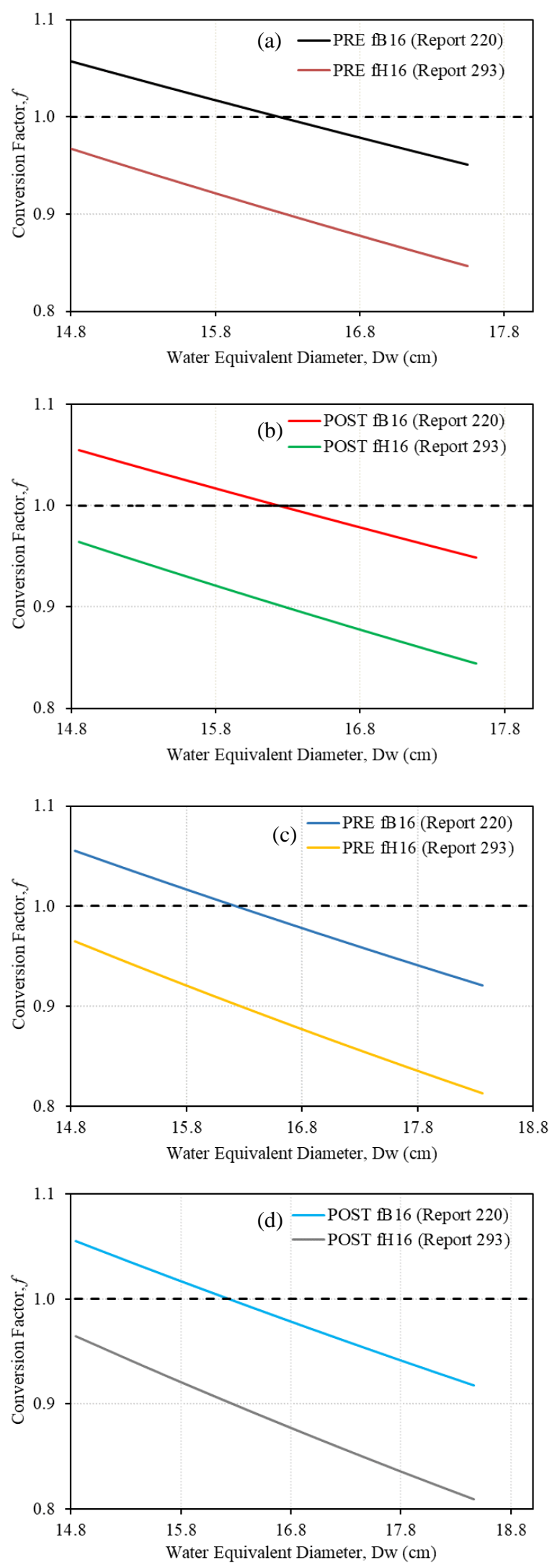

Figure 5: The conversion factor for calculating SSDE based on water equivalent diameter, and the difference absorbed dose between $\mathrm{f}^{\mathrm{H} 16}$ and $\mathrm{f}^{\mathrm{B} 16}$. (a) CT Scanner Toshiba Alexion 16 pre-contrast with the percentage difference is $9.72 \%$. (b) CT Scanner Toshiba Alexion 16 post-contrast with the percentage difference is $9.79 \%$. (c) CT Scanner GE Medical System Optima CT660 pre-contrast with the percentage difference is $10.08 \%$. (d) CT Scanner GE Medical System Optima CT660 post-contrast with the percentage difference is $10.19 \%$.

Figure 6 shows a positive relationship between the SSDE pre-contrast value and the SSDE post-contrast value for the two CT Scan modalities and the conversion factor values of $\mathrm{f}^{\mathrm{H} 16}$ and $\mathrm{f}^{\mathrm{B} 16}$, namely CT Scanner Toshiba Alexion $16 \mathrm{f}^{\mathrm{B} 16}$, CT Scanner Toshiba Alexion $16 \mathrm{f}^{\mathrm{H} 16}$, CT Scanner GE Medical System Optima CT660 $\mathrm{f}^{\mathrm{B} 16}$ and CT Scanner GE Medical System Optima CT660 $\mathrm{f}^{\mathrm{H} 16}$ with $\mathrm{R}^{2}$ values were $0.9944,0.9944,0.9933$, and 0.9933 . This indicates that the increase in the SSDE pre- contrast value is accompanied by an increase in the SSDE post-contrast value. Figure 7 shows the box and whisker plot of the SSDE pre-contrast agent value and the SSDE postcontrast agent value for the two CT Scan modalities with conversion factor values $\mathrm{f}^{\mathrm{B} 16}$ and $\mathrm{f}^{\mathrm{H} 16}$. The difference in mean value of SSDE pre-contrast agent and mean value of SSDE post-contrast agent CT Scanner Toshiba Alexion $16 \mathrm{f}^{\mathrm{B} 16}$, CT Scanner Toshiba Alexion $16 \mathrm{f}^{\mathrm{H} 16}$, CT Scanner GE Medical System Optima CT660 f ${ }^{\text {B16 }}$ and CT Scanner GE Medical System Optima CT660 $\mathrm{f}^{\mathrm{H} 16}$ were $0.27 \%, 0.34 \%, 0.48 \%$ and $0.60 \%$. This indicates that the difference between SSDE pre-contrast and SSDE post-contrast is not significant.

Based on AAPM report 220 and AAPM report 293 to calculate the SSDE metric used is Dw because Dw considers tissue attenuation to estimate SSDE can be more accurate in body areas that contain various tissue compositions and densities. Therefore, to consider the change in Dw affecting SSDE we normalized dose coefficient (NDC). The NDC change values were obtained for the CT Scanner Toshiba Alexion with a conversion factor $\mathrm{f}^{\mathrm{B} 16}$, CT Scanner 
Toshiba Alexion 16 conversion factor $\mathrm{f}^{\mathrm{H} 16}$, CT Scanner GE Medical System CT660 conversion factor $\mathrm{f}^{\mathrm{B} 16}$, and CT Scanner GE Medical System CT660 conversion factor $\mathrm{f}^{\mathrm{B} 16}$ were $0.27 \%, 0.34 \%, 0.47 \%$ and $0.59 \%$. The NDC value in this study is acceptable because the SSDE calculation can be accepted with an error below $20 \%$ [26].

The results of our study found that the CT head contrast SSDE examination can be calculated using only the Dw pre-contrast or Dw post-contrast values. Because there is no significant effect of contrast agent on $\mathrm{Dw}$ value. So that an approach can be made to one of the Dw values on the axial image of the patient. For further studies, the effect of agent contrast on Dw value can be done with variations of $\mathrm{kVp}$. Because when energy decreases, the iodine attenuation increases relative to the air increase [27]. It is hoped that the process of obtaining dose optimization for CT head contrast examination will occur.
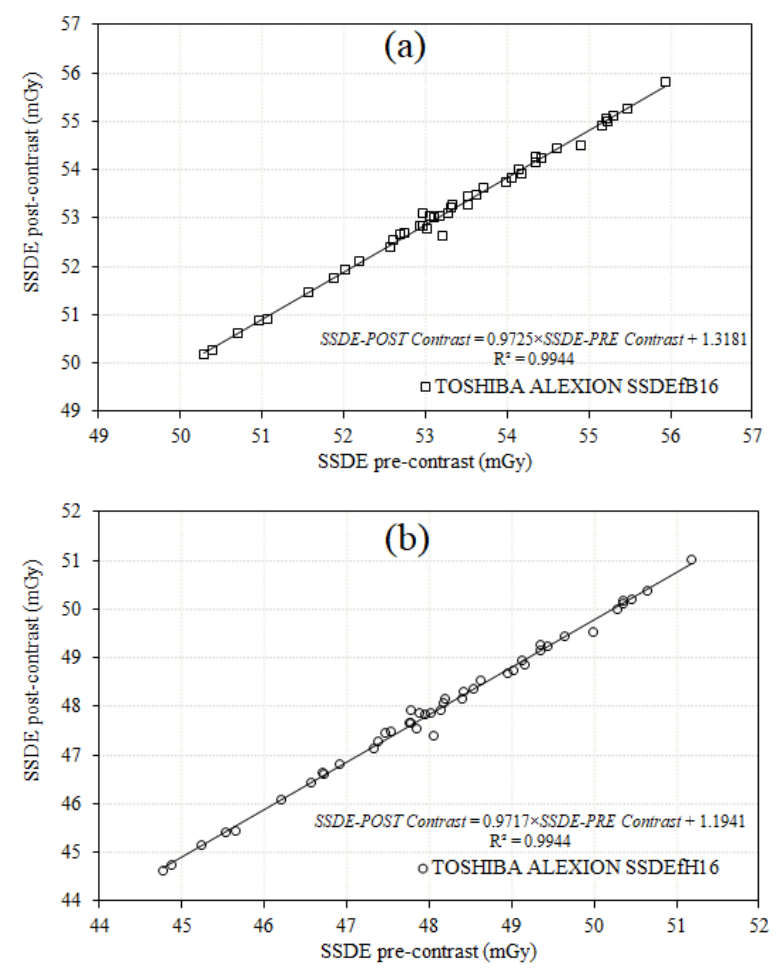
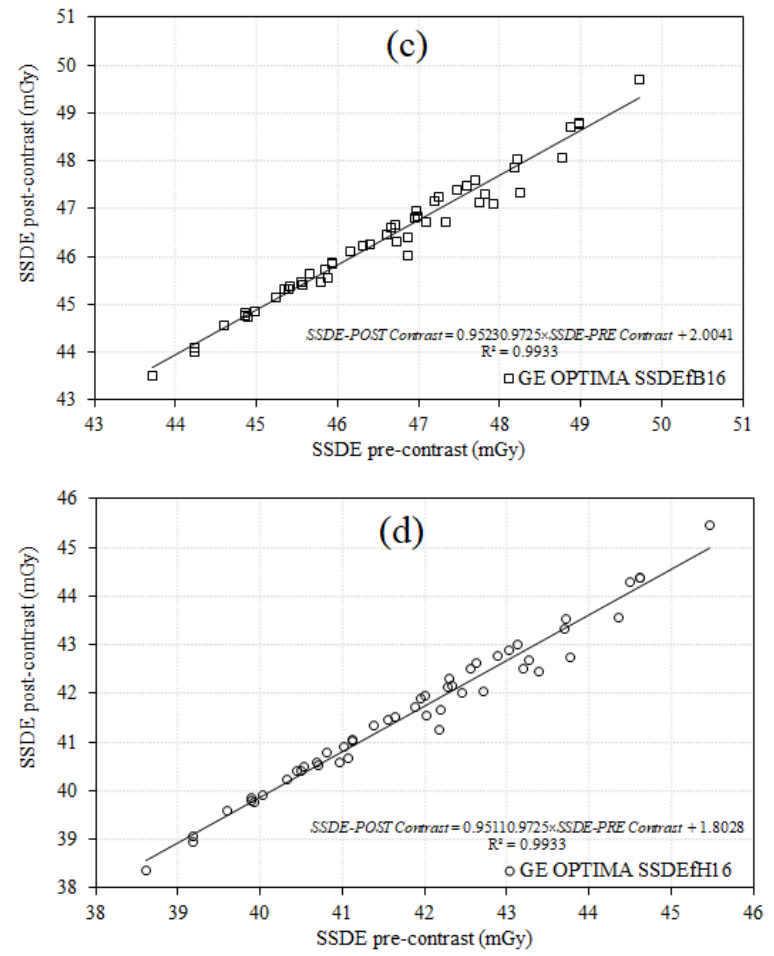

Figure 6: Scatterplot of size-specific dose estimate precontrast vs size-specific dose estimate post-contrast for conversion factor value $\mathrm{f}^{\mathrm{H} 16}$ and $\mathrm{f}^{\mathrm{B} 16}$ to know the relationship between them both. (a) SSDE $\mathrm{f}^{\mathrm{B} 16} \mathrm{CT}$ Scanner Toshiba Alexion 16. (b) SSDE $\mathrm{f}^{\mathrm{H} 16} \mathrm{CT}$ Scanner Toshiba Alexion 16. (c) SSDE f ${ }^{\mathrm{B} 16} \mathrm{CT}$ Scanner GE Medical System Optima CT660. (d) SSDE $\mathrm{f}^{\mathrm{H} 16}$ CT Scanner GE Medical System Optima CT660.
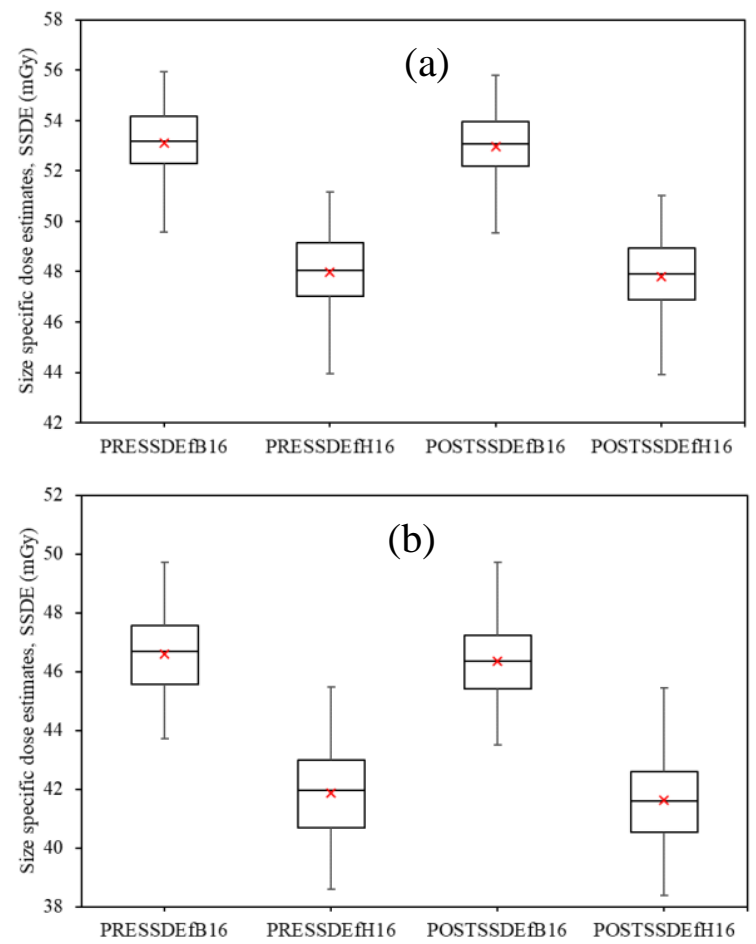
Figure 7: Box and whisker plot of size-specific dose estimates with conversion factor value $\mathrm{f}^{\mathrm{B} 16}$ and $\mathrm{f}^{\mathrm{H} 16}$ to know the relationship between them both. (a) CT Scanner Toshiba Alexion 16. (b) CT Scanner GE Medical System Optima CT660.

\section{CONCLUSION}

We did not see the effect of agent contrast on Dw and SSDE values on CT head examination. Statistical analysis showed that the $\mathrm{P}$-value $>0.05$ indicated that the difference between Dw pre- and post- contrast was not significant. SSDE on CT head examination with contrast agent can be approached on one of the Dw values.

\section{ACKNOWLEDGMENT}

This work was funded by the World Class Research University (WCRU), Diponegoro University, No. 11808/UN7.61/PP/2021.

\section{REFERENCES}

[1]. Lee KH, Lee JM, Moon SK, Baek Jh, Park JH, Flohr TG, Kim KW, Kim SJ, Han JK, Choi BI. Attenuation-based Automatic Tube Voltage Selection and Tube Current Modulation for Dose Reduction at Contrast-enhanced Liver CT. Radiology. 2012; 265: 437 - 447.

[2]. Shuaib W, Tiwana, MH, Chokshi FH, Johnson JO, Bedi H, Khosa F. Utility of CT head in the acute setting: value of contrast and non-contrast studies. Irish Journal of Medical Science. 2015; 184: 631 635.

[3]. Sahbaee P, Abadi E, Segras WP, Marin D, Nelson RC, Samei E. The Effect of Contrast Medium on Radiation Dose in CT: Part II - A Systemic Evaluation across 58 Patient Models1. Radiology. 2017; 283: 749 - 757.

[4]. Solberg TD, Iwamoto KS, Norman A. Calculation of radiation dose enhancement factors for dose enhancement therapy of brain tumors. Phys. Med. Biol. 1992;37:439 - 443.

[5]. Hricak H, Brenner DJ, Adelstein SJ, Frush DP, Hall EJ, Howell RW, McCollough CH, Mettler FA, Pearce MS, Suleiman OH, Thrall JH, Wagner LK. Managing radiation use in medical imaging: a multifaceted challenge. Radiology. 2011; 258: 889 $-905$.

[6]. Turner AC, Zankl M, DeMarco JJ, Cagnon CC, Zhang D, Angel E, Cody DD, Stevens DM, McCollough CH, McNitt-Gray MF. The feasibility of a scanner-independent technique to estimate organ dose from MDCT scans: using CTDIvol to account for differences between scanners. Med. Phys. 2010; 37: 1816 - 1825.

[7]. Bauhs JA, Vrieze TF, Primak AN, Bruesewitz MR, McCollough CH. CT Dosimetry: Comparison of Measurement Techniques and Devices. Radiographics. 2008; 28: 245 - 253.

[8]. Wang J, Duan X, Christner JA, Leng S, Yu L, McCollough CH. Attenuation-based estimation of patient size for size-specific dose estimation in CT. Part I. Development and validation of methods using the CT image. Med. Phys. 2012; 39: $6764-6771$.

[9]. Franck C, Vandenoorde C, Goethals I, Smeets P, Achten E, Verstraete K, Thierens Hm Bacher K. The role of Size-Specific Dose Estimate (SSDE) in patient-specific organ dose and cancer risk estimation in pediatric chest and abdominopelvic CT examinations. Eur. Radiol. 2016; 26(8); 2646 2655.

[10]. Huda W, Mettler FA. Volume CT dose index and dose-length product displayed during CT: What good are they?. Radiology. 2011; 258: $236-242$.

[11]. McCollough CH, Leng S, Yu L, Cody DD, Boone JM, McNitt-Gray MF. CT dose index and patient dose: They are not the same thing. Radiology. 2011; 259: $311-316$.

[12]. Larson DB, Wang LL, Podberesky DJ, Goske MJ. System for verifiable CT radiation dose optimization based on image quality. Part I. Optimization model. Radiology. 2013; 269: 167 176. 
[13]. Larson DB, Malarik RJ, Hall SM, Podberesky DJ. System for verifiable CT radiation dose optimization based on image quality. Part II. Process control system. Radiology. 2013; 269: 177 $-185$.

[14]. American Association of Physicists in Medicine. Report of AAPM TG 204: Size-specific dose estimates (SSDE) in pediatric and adult body CT examinations. AAPM. 2011: $1-22$.

[15]. Brink JA and Morin RL. Size-specific Dose Estimation for CT: How Should It be Used and What Does It Mean?. Radiology. 2012; 265: 666 668.

[16]. Kalender WA. X-Ray Computed Tomography. Phys Med Biol. 2014; 51: R29 - R43.

[17]. American Association of Physicists in Medicine. Report of AAPM TG 220: Use of water equivalent diameter for calculating patient size and sizespecific dose estimates (SSDE). AAPM. 2014: 1 23.

[18]. Moore BM, Brady SL, Mirro AE, Kaufman RA. Size-specific dose estimate (SSDE) provides a simple method to calculate organ dose for pediatric CT examinations. Med. Phys. 2014; 41(7): 1 - 10 .

[19]. American Association of Physicists in Medicine. Report of AAPM TG 293: Size-Specific Dose Estimate (SSDE) for Head CT. AAPM. 2019: 1 24.

[20]. Viggiano B, Rose S, Szczykutowicz TP. Effect of contrast agent administration on water equivalent diameter in CT. Med. Phys. 2021; 48: 1117 - 1124.

[21]. Nitasari A, Anam C, Budi WS, Wati AL, Syarifudin S, Dougherty G. Comparisons of waterequivalent diameter measured on images of abdominal routine computed tomography with and without contrast agent. Atom Indonesia. 2020.

[22]. Leng S, Shiung M, Duan X, Yu L, Zhang Y, McCollough $\mathrm{CH}$. Size-specific dose estimates for chest, abdominal, and pelvic CT: effect of intrapatient variability in water-equivalent diameter. Radiology. 2015;276: $184-190$.
[23]. Anam C, Haryanto F, Widita R, Arif I, Dougherty G. Automated Calculation of water equivalent diameter (Dw) based on AAPM Task Group 220. J Appl Clin Med Phys. 2016; 17(4): 320 - 333.

[24]. McCollough S, Moen T, Schneider J, Vrieze T, Leng S, McCollough C. Impact of Tube Potential On Water Equivalent Diameter and Size Specific Dose Estimate Values for Head, Chest, and Abdomen CT Scans, Mayo Clinic, Rochester, MN Presented at the 2019 AAPM Summer Meeting, San Antonio Texas, USA. https://doi.org/10.1002/mp.13596

[25]. Amato E, Salamone I, Naso S, Bottari A, Gaeta M, Blandino A. Can Contrast Media Increase Organ Doses in CT Examinations? A Clinical Study. AJR. 2013; 200: 1288 - 1293.

[26]. McCollough C, Bakalyar DM, Bostani M, et al. Use of water equivalent diameter for calculating patient size and size-specific dose estimates (SSDE) in CT: the report of AAPM task group 220. AAPM Report 2014; 2014: 6 - 23.

[27]. Yu L, Bruesewitz MR, Thomas KB, Fletcher JG, Kofler JM, McCollough CH. Optimal tube potential for radiation dose reduction in pediatric CT: principles, clinical implementations, and pitfalls. Radiographics. 2011; 31:835 - 848.

\section{Cite this article as :}

Moh. Shofi Nur Utami, Heri Sutanto, Choirul Anam, Muharam Budi Laksono " Effect of Contrast Agent Administration on Size-Specific Dose Estimates (SSDE) Calculations based on Water Equivalent Diameter in CT Head Examinations", International Journal of Scientific Research in Science and Technology(IJSRST), Print ISSN : 2395-6011, Online ISSN : 2395-602X,Volume 8, Issue 3, pp.563-571, May-June-2021. Available at doi $\quad:$ https://doi.org/10.32628/IJSRST2183124 Journal URL : https://ijsrst.com/IJSRST2183124 